\title{
A 25-Year History of Spatial and Temporal Trends in Wildfire Activity in Oregon and Washington, U.S.A.
}

\author{
Michael G. Wing ${ }^{1} \&$ Justin Long ${ }^{1}$ \\ ${ }^{1}$ Forest Engineering, Resources and Management, Oregon State University, Corvallis, Oregon, USA \\ Correspondence: Michael G. Wing, Forest Engineering, Resources and Management, Oregon State University, \\ Corvallis, Oregon, USA. Tel: 1-541-737-4009. E-mail: Michael.wing@oregonstate.edu
}

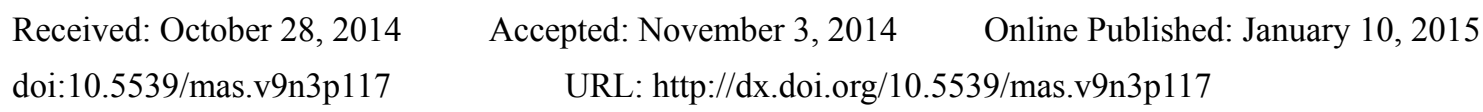

\begin{abstract}
We examined spatial and temporal trends in large fire incidents $(>400$ ha) in Oregon and Washington. Our primary objectives were to examine whether patterns existed in the spatial and temporal distribution of large fires and to explore the relationship of patterns to climate variables using a geographic information system. We analyzed a historical fire database containing over 1000 fire incidents over a 25-year time period (1984 - 2008). We compared this fire database to climate variables representing historical estimates of average monthly maximum temperature, average monthly minimum temperate, average monthly dewpoint, and average monthly precipitation. Results showed an increasing trend in fire frequency, extent, magnitude, and fire season duration. Geospatial analytical techniques such as nearest neighbor analysis, quartic kernel density estimation, and quadrat analysis identified spatial patterning and hot spots of fire occurrence and size. The relationship of fire occurrence and size to climate variables was generally statistically indiscernible in our analysis results although some correlation was evident when fires were analyzed separately according to burn severity.
\end{abstract}

Keywords: wildfire tends, geospatial, forestry

\section{Introduction}

In recent decades wildfire in the western United States has been growing in frequency and extent (Skinner and Chang 1996; Calkin et al., 2005; Westerling et al., 2006; Miller and Safford 2012). The legacy of fire suppression and changing climate patterns has resulted in an increasing prevalence of large wildfires in western North America (Skinner and Chang, 1996; Calkin et al., 2005; Thomson et al., 2007; Cochrane et al., 2012). In particular, large wildfire occurrence has increased from the early 1980s (Skinner and Chang 1996, Westerling et al., 2006). Since 2000, federal wildfire expenditures in the United States have averaged over $\$ 1$ billion annually (Calkin et al., 2005). As wildfire suppression costs continue to rise, wildfire extent and frequency particularly in the western United States has drawn greater attention. Previous studies suggest that an increases in wildfire activity may be a result of longer wildfire durations and longer wildfire seasons (Wotton and Flannigan 1993; Westerling et al., 2006). However, others have focused on the impact of regional climate patterns on the frequency and extent of wildfire in regions of the United States and Canada (Flannigan and Harrington 1988; Swetnam and Betancourt 1990; Westerling and Swetnam 2003). Although wildfire occurrence in the western United States has been increasing in recent decades, the significance of climate variables on wildfire extent and magnitude has not been widely documented on large spatial and temporal scales.

We examined the spatial and temporal trends in fire behavior and climate variables in Oregon and Washington for a 25-year time period from 1984 to 2008. Our primary objectives were to identify, spatially and temporally, where changes in fire behavior were most pronounced, and whether associated climate variables offered any explanation for patterns in fire behavior. We investigated spatial and temporal trends in climate variables and fire behavior through the application of geospatial and other analytical techniques to evaluate spatial patterning, and assessed the degree of significance of climate conditions in explaining variation in fire behavior. To our knowledge, no prior analysis has considered such an extensive landscape and collection of variables in researching historical fire patterns.

\section{Materials and Methods}

Fire History

Spatially referenced fire records were obtained for Oregon and Washington from the Monitoring Trends in Burn 
Severity (MTBS) project which included large fire occurrences ( $>400$ ha) across all ownerships from 1984 2008 (Figure 1). Both fire occurrence and severity were determined through data acquired by Landsat Thematic Mapper (TM) imagery at a spatial resolution of $30 \mathrm{~m}$. Landsat data that were collected both before and after each fire were used to classify fire conditions. Pre- and post-fire images were compared and categorized into five discrete classes allowing for a quantitative assessment of fire severity. These classes included (Table 1) unburned/unchanged, low severity, moderate severity, high severity, and increased post-fire response (MTBS 2007). Previous studies have used similar fire severity datasets to explore trends in fire severity (Odion et al., 2004; Thompson et al., 2007).

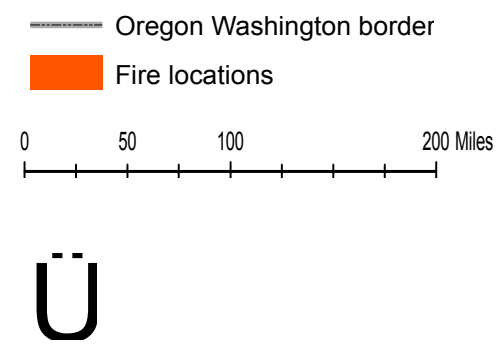

Figure 1. Large fire locations (>1000 acres) in Oregon and Washington between 1984 and 2008

Table 1. Burn severity codes

\begin{tabular}{ll}
\hline \multicolumn{1}{c}{ Burn Severity Codes } \\
\hline $1=$ Unburned to Low \\
$2=$ Low \\
$3=$ Moderate \\
$4=$ High \\
$5=$ Increased Greenness \\
$6=$ Non-Processing Area Mask \\
\hline
\end{tabular}

Terminology referring to post fire effects is often applied inconsistently and used interchangeably (Keeley 2009). The MTBS project uses the terms burn severity and fire severity interchangeably according to the definition of burn severity provided by the National Wildfire Coordinating Group (NWCG). Burn severity is defined as the "Degree to which a site has been altered or disrupted by fire; loosely, a product of fire intensity and residence time" (NWCG 2005). We use the definition of burn severity provided by the NWCG in order to maintain consistency.

\section{Climate Data}

Climate datasets were obtained from Parameter-elevation Regressions on Independent Slopes Model (PRISM) at a spatial resolution of $4 \mathrm{~km}$. We analyzed continuous, digital grid estimates of average monthly maximum temperature, average monthly minimum temperate, average monthly dewpoint, and average monthly precipitation for the time period of 1984 - 2008. Our analysis examined monthly climate records associated with months recording large wildfires.

Each spatial data layer was assigned to a common spatial projection to ensure that comparisons could be made consistently between all data layers. A GIS overlay process was used to populate individual fire records with information on fire severity, elevation, and climate.

\section{Point Pattern Analysis}

We used spatial statistics to investigate the spatial distribution of fire locations across the entire study area (Wong and Lee, 2005). Several spatial analytical techniques are available to assist in the interpretation of fire locations. One such technique is the application of point pattern analysis to investigate spatial trends (Wong and Lee, 2005).

Point pattern analysis techniques quantify patterns of the distribution of spatial data (Boots and Getis 1998). Patterns that can be detected using point pattern analysis include random, clustered, and dispersed (regular) patterns. Observations that follow random distributions indicate that there is a low probability of geographic influence on spatial distribution. A clustered pattern is a collection of grouped observations while dispersed 
patterns occur at regular intervals. While point pattern analysis provides a means for evaluating geographic phenomena, we are unaware of any previous study that has applied point pattern analysis to fire occurrence. Recent studies have used point pattern analysis techniques to analyze the distribution of crime incidents on U.S. Forest Service lands (Wing and Tynon, 2006; Wing and Tynon, 2008).

In this study we used several methods of point pattern analysis, including nearest neighbor analysis and quadrat analysis. We conducted point pattern analyses by calculating the geometric centroid of each fire and using the centroid coordinates in our analyses. In addition we use a quartic kernel density analysis to identify fire hotspots and validate hotspots recognized by quadrat analysis. Hotspots are described by Harries (1999) as "a condition indicating some form of clustering in a spatial distribution" (p. 112). Our hotspot analyses are based on the spatial aggregation of large fire observations over a 25 year period.

Nearest Neighbor Analysis

Nearest neighbor analysis determines whether an observed pattern is clustered, dispersed, or random by comparing the average distance between adjacent points to the expected average distance of points from a complete random distribution. If the observed average distance is significantly greater than that of a random pattern we can say that the observed point pattern is more dispersed than a random pattern. Similarly, a point pattern is said to be clustered if the observed average distance between nearest neighbors is found to be less than that of a random pattern (Wong \& Lee, 2005).

Density Diagrams

The MTBS database contained over 1000 large fires (>400 ha) for the time period of 1984 - 2008. Fire centroids were used to identify fire hotspots through quartic kernel density analysis. Quartic kernel analysis indicates spatial clustering by displaying the distribution of features or values per unit area using a kernel function to fit a smoothed surface to each point (Mitchell 1999). Results indicate the density of features, or variation in feature attribute values. We based our hotspot analysis on the spatial distribution of fire observations while considering attribute values of hectares and severity.

\section{Quadrat Analysis}

Quadrat analysis is a method of point pattern analysis for quantifying the distribution of points by examining changes in point density across the landscape (Wong \& Lee, 2005). Unlike a nearest neighbor analysis that considers distances between points, quadrat analysis is based on measures of dispersion within square or rectangular cells mapped upon a landscape. Quadrats may either be scattered as isolated cells, or contiguous as a grid superimposed on the study area with the variable of interest being the observed counts per cell. A Chi-squared distribution tests the null hypothesis of complete randomness by comparing the observed frequency to the expected frequency for each cell (Boots \& Getis 1988).

The identification of an appropriate quadrat size requires careful consideration. Large quadrats tend to produce a situation a similar number of points in all of the quadrats resulting in bias towards a dispersed pattern. However, if the quadrats are too small they may produce a bias in favor of a random pattern by dividing clusters (Boots $\&$ Getis 1988). There are several guidelines for determining an appropriate quadrat size. A general rule of thumb suggested by Boots and Getis (1988) is that the appropriate size of a quadrat can be approximated using the following equation.

$$
\text { Quadrat area }=2 \mathrm{~A} / \mathrm{r} \text {, }
$$

Where $\mathrm{A}=$ Total area of the study region and $\mathrm{r}=$ the total number of observation.

Spatial Autocorrelation

We applied cluster mapping techniques to measure the degree of similarity between attribute values of adjacent points. We used Moran's Index and Getis Ord general G-statistic to measure the magnitude of clustering among points. Both procedures examine the spatial distribution of points and determine the degree of similarity between adjacent point attribute values.

\section{Moran's I}

Moran's Index (Moran 1950), also called Moran's I, is a measure of spatial autocorrelation that combines the measures for location proximity and attribute similarity into a single index (Wong \& Lee, 2005). Observed values of neighboring points are compared to expected values for the entire study area. The index value is positive if neighboring features share similar values, either high or low. A negative index value indicates neighboring feature values are different. If there is no significant spatial autocorrelation then $\mathrm{I}=0$. 
Moran's I determines whether spatial autocorrelation exists in the data by measuring the attribute similarity of nearby points. However, it cannot distinguish the difference between similarities in high values (hotspots) or low values (cold spots).

\section{Getis-Ord General G-statistic}

The general G-statistic (Getis \& Ord, 1992) is capable in detecting the presence of hot spots or cold spots over the entire study area (Wong and Lee 2005). While Moran's I measures the similarity of neighboring point values, the general G-statistic indicates whether clusters are composed of high or low values. The general G-statistic measures how high or low nearby values are, and compares this to a measure of how high or low the values are over the entire study area (Mitchell, 2005).

The General G-statistic measures concentrations of high or low values over the entire study area. A positive Z score indicates that high attribute values are spatially clustered while a $\mathrm{Z}$ score that is negative indicates that low attribute values are spatially clustered.

However, the G-statistic was only designed to work with positive attribute values. Attributes including negative values such as average dewpoint and average minimum temperature were transformed using a monotonic transformation to preserve the order of the original observations.

\section{Statistical Analysis}

Due to a lack of normality in the distribution of burn area data, Spearman rank-order correlation coefficients were computed between annual burn area data and climate variables. Two-way analysis of variance was used to test for differences among annual observations of fire size, average precipitation, average maximum temperature, average minimum temperature, and average dewpoint. All hypothesis tests were 2-tailed and at the 0.05 significance level. Tukey-Kramer multiple comparison tests were used to detect differences among means. We used linear regression to reveal how various combinations of variables may influence annual burned

\section{Results}

\section{Climate Variables}

For our analysis, we associated climate information with fire areas through a GIS overlay of spatial climate layers on fire polygons. Consequently, our interpretation of trends in climate is limited to the areas associated with large fire occurrences. Annual and decadal trends in monthly climate variables (Figure 2) include average monthly maximum temperature, average monthly minimum temperate, average monthly dewpoint, and average monthly precipitation.

Our results indicate that the late 1980s experienced slightly higher average precipitation that continue into the early 1990s (Figure 2). This period of high precipitation corresponds to a notable decrease in annual hectares burned for the same time period (Figure 3). Despite events of high precipitation in 2001 and 2003, average precipitation has remained fairly consistent since the 1980s. Average minimum temperature, average maximum temperature, and average dewpoint experienced little change from the 1980s to the 1990s. However each variable increased significantly from the 1990 s to the 2000 s which corresponds to a significant increase in total hectares burned for the same time period. 


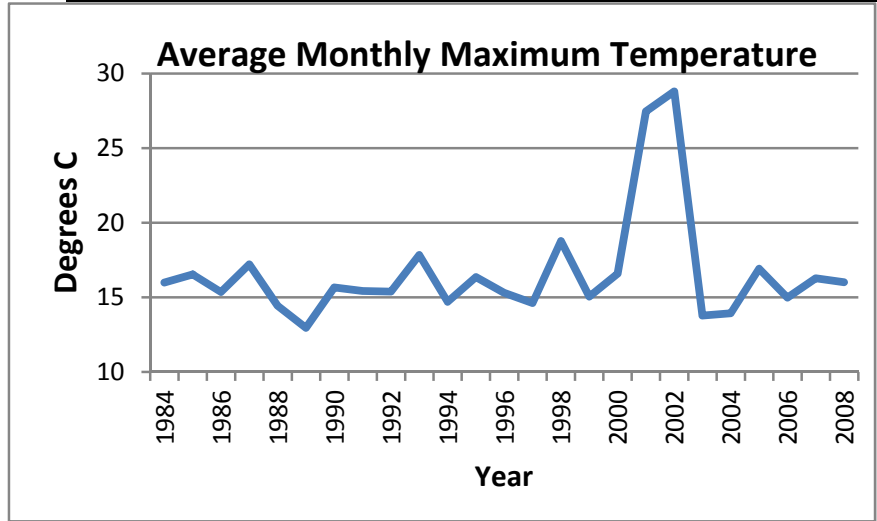

Average Maximum Temperature per Decade

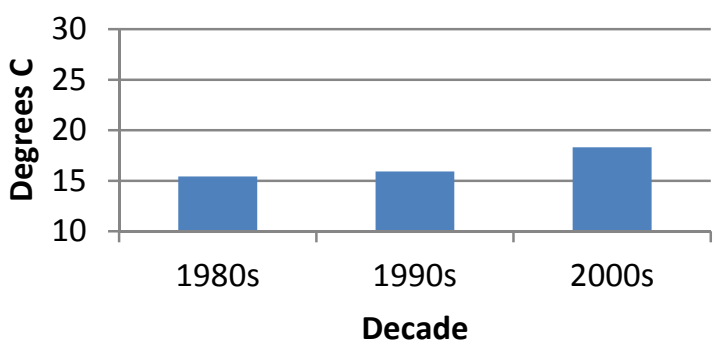

Average Monthly Minimum Temperature
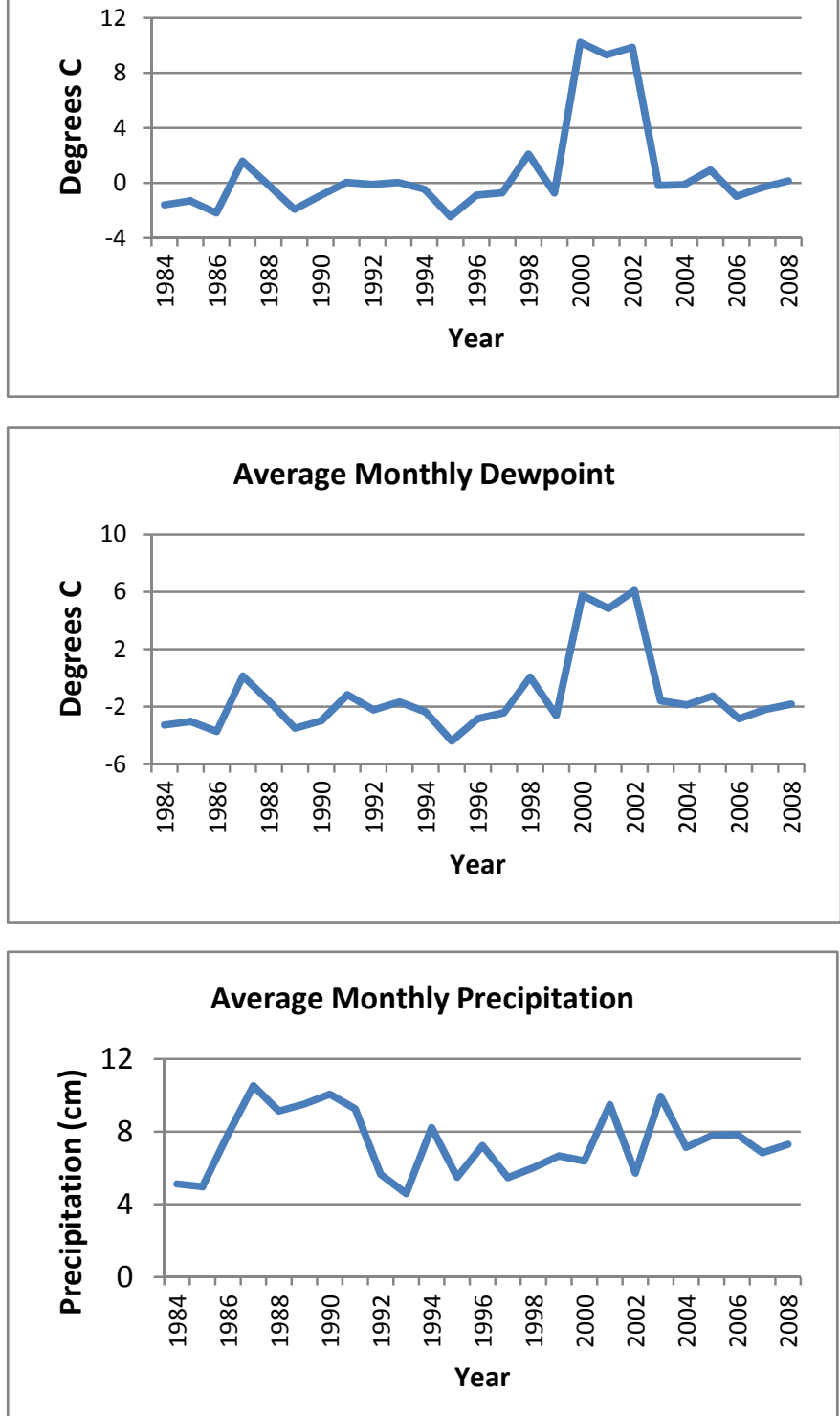

Average Minimum Temperature per Decade

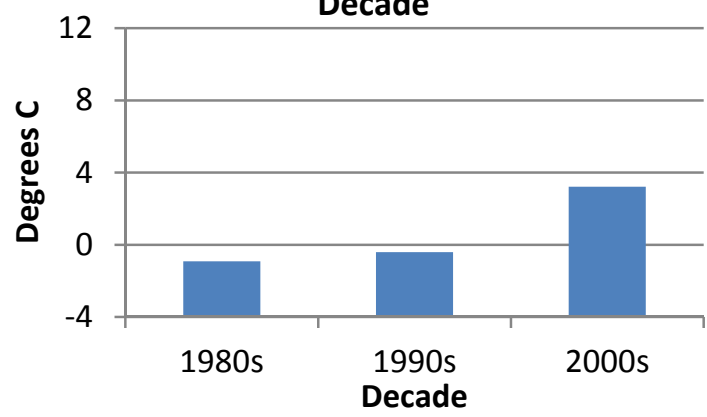

Average Dewpoint per Decade

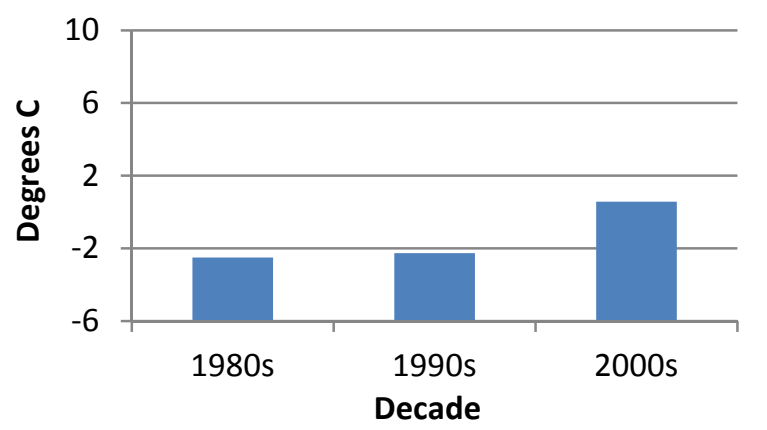

\section{Average Precipitation per Decade}

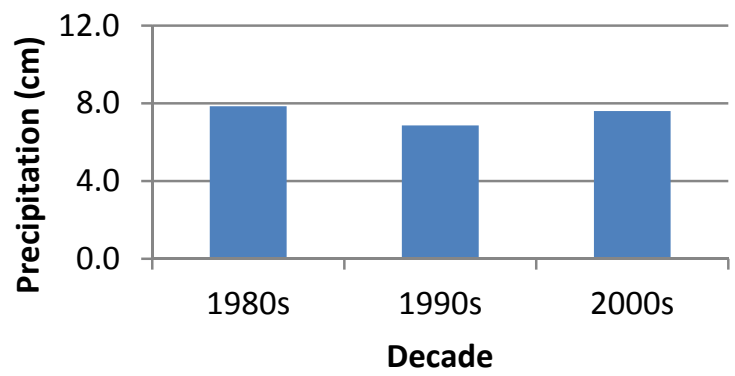

Figure 2. 

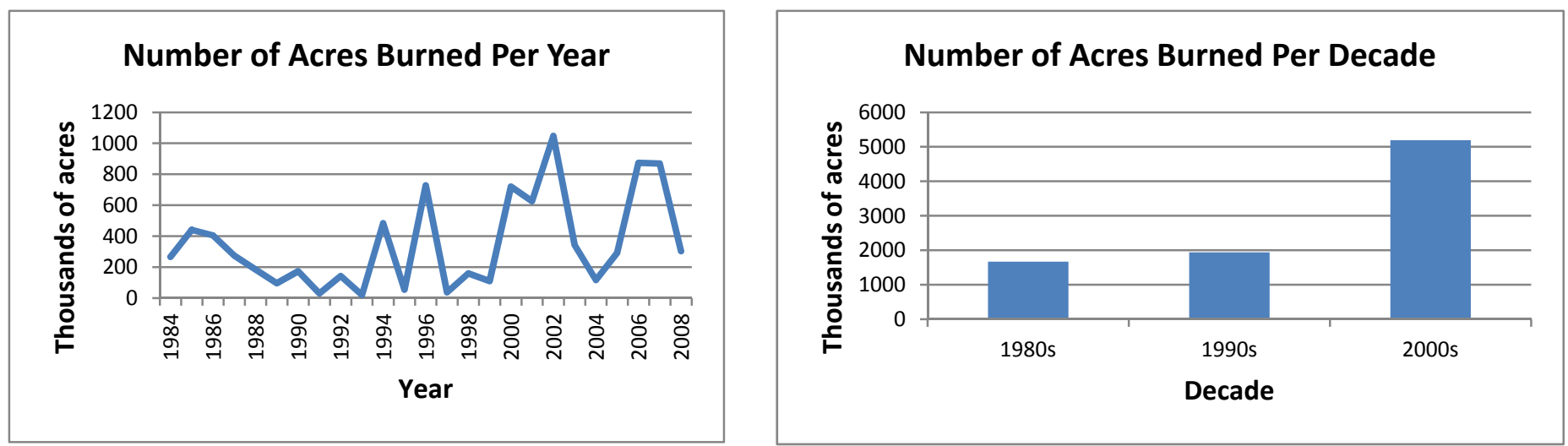

Figure 3. (A) Acres burned per year and (B) Acres burned per decade by large fires (>1000 acres)

Average minimum temperature and average dewpoint appear to be significantly correlated (Figure 2). High points in 1987, 1998, and 2005 and low points in 1986, 1989, 1995, 1999, and 2006 are reflected by average minimum temperature and average dewpoint as well as a 4-year period of high values in 1990-1994. A dramatic increase is noted from 2001 to 2003 which corresponds to a peak in annual hectares burned beginning in 2000 (Figure 3).

In addition both minimum temperature and dewpoint increase gradually from the 1980s to the 1990s. A more dramatic trend is apparent for the 2000 decade which is reflected in hectares burned (Figure 3).

\section{Hectares Burned}

Hectares burned as a result of large fires were lowest in 1989, 1990, 1991, 1992, 1993, 1995, 1997, 1998, 1999, and 2004 (Figure 3). However, burned area is highest in 1985, 1986, 1994, 1996, 2000, 2001, 2002, 2006, and 2007 with over 400,000 hectares burned. Peak wildfire activity is reported for years 2002, 2006, and 2008 with over 800,000 hectares burned each year. There are two periods of noteworthy fire activity. Each of which is in the most recent decade. Large fires burned over 600,000 hectares in 2000, 2001, and 2002, and over 800,000 hectares in 2006 and 2007. An oscillating pattern in hectares burned reveals that periods of low activity are followed by several years of active fire behavior, while periods of active fire behavior are followed by several years of low fire activity.

However, considering a broader temporal scale reveals an increasing trend in average annual hectares burned per decade. A gradual increase in hectares burned per decade occurs from the 1980s to the 1990s. However, a more dramatic increase in hectares burned is present from the 1990s to the 2000s as average hectares burned increases from nearly 200,000 hectares per year in the 1990 s to over 500,000 hectares per year in the 2000s.

\section{Fires Per Year}

The average number of large fires per year follows a similar trend to that of hectares burned. Less than 20 large fires were reported for 1989, 1991, 1993, 1995, and 1997. However, over 50 large fires were reported in 1985, 1994, 1996, 2000, 2001, 2002, 2006, 2007, and 2008 (Figure 4). Several inactive fire years are followed by active fire years, while active fire years are followed by inactive years. Two periods reporting significant wildfire activity correspond to peaks in hectares burned per year. Over 50 large fires were reported in 2000, 2001, and 2002, and over 80 large fires in 2006 and 2007. 

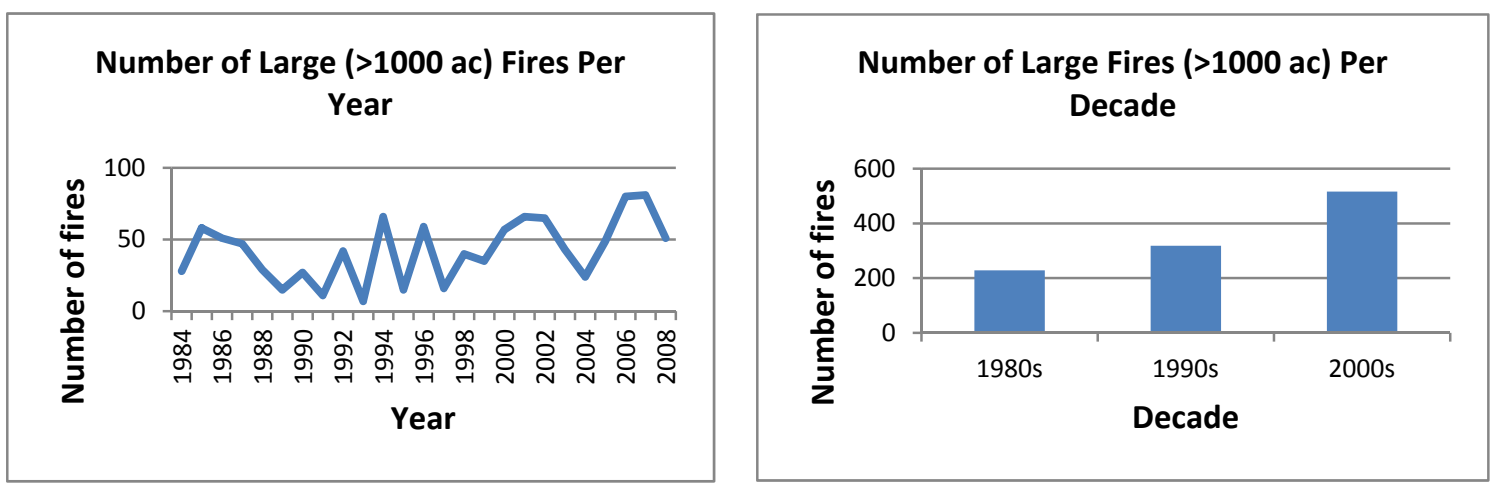

Figure 4. (A) Number of large fires ( $>1000$ acres) per year and (B) number of large fires ( $>1000$ acres) per decade

Considering the annual number of fires occurrences on a decadal scale reveals an increasing trend in each decade. Over 200 large fires were reported in the 1980s. This trend continued through the 1990s with over 300 large fires being reported, and into the 2000s with over 500 .

Fire Severity

We determined the proportion of total annual burned area for each severity class by summarizing the 30 meter resolution fire severity grids (Figure 5). Low severity wildfires represented over $80 \%$ of the total area burned in $1984,1985,1993$, and 2000 and less than $60 \%$ of the total burned area in 1989, 1990, 1995, 2002, 2003, 2006, and 2007 (Figure 5).
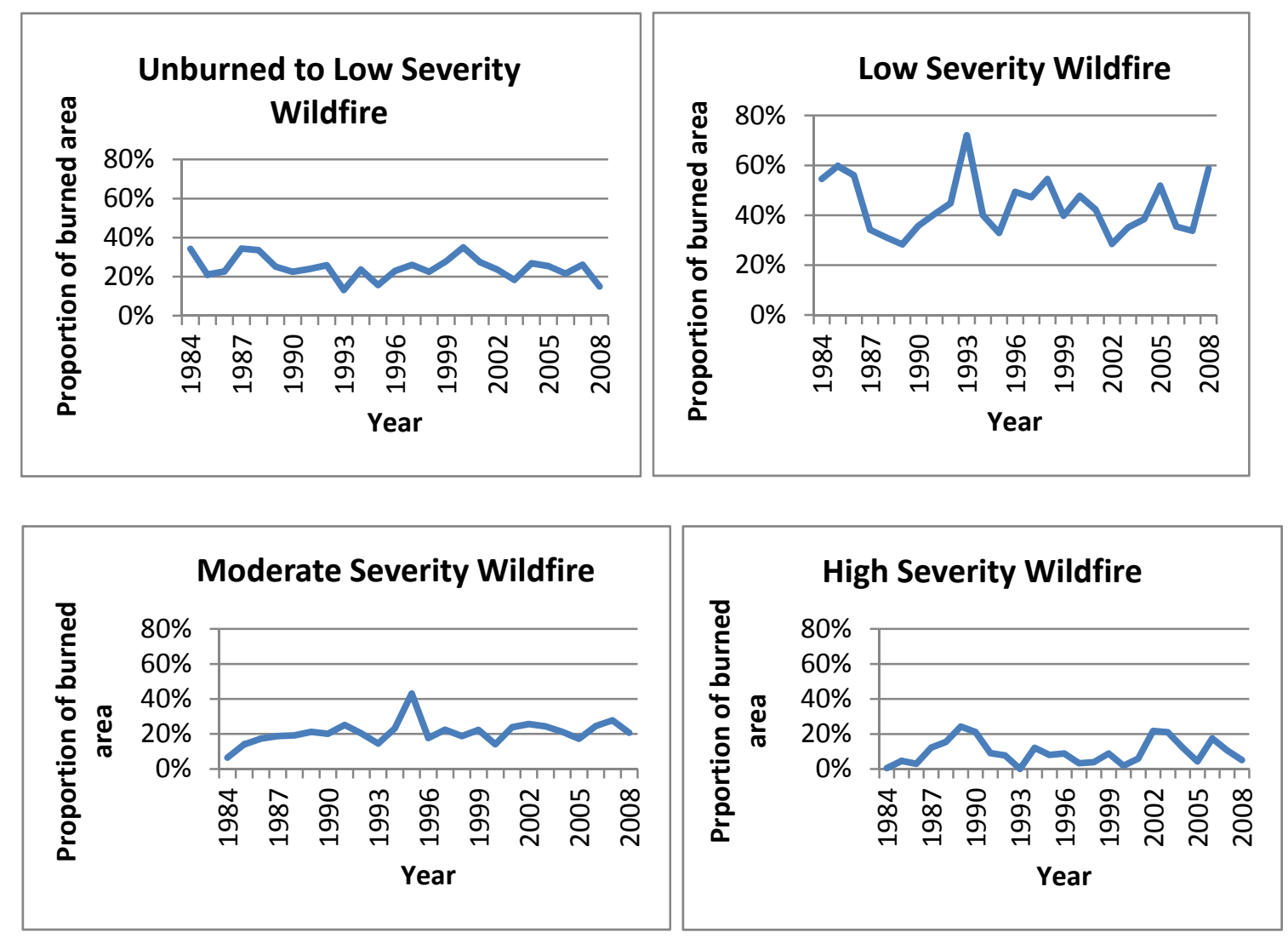


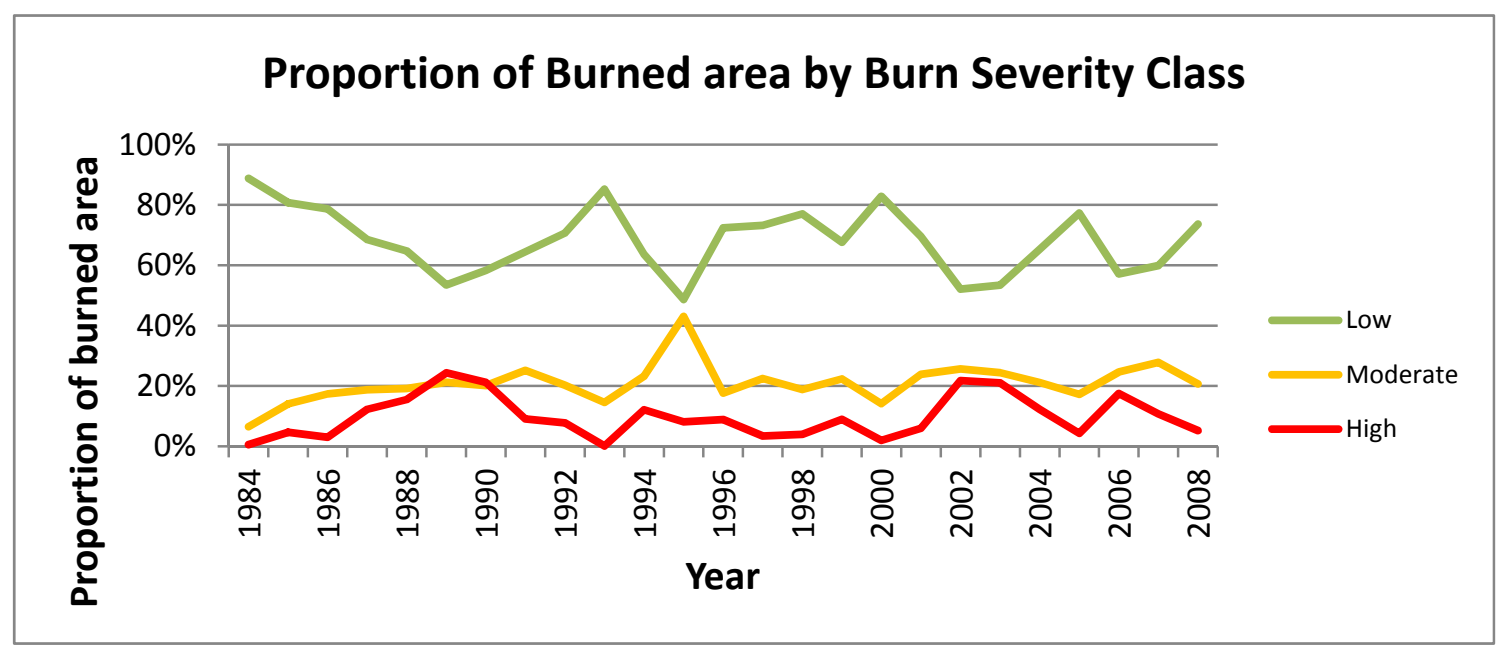

Figure 5. Proportion of annual burned area by low, moderate, and high severity fire

Moderate severity wildfire covered over 25\% of the burned area in 1991, 1995, 2002, 2006, and 2007 and less than $15 \%$ in 1984,1985 , and 2000 . There is a notable increase, however, in 1995 where moderate severity wildfire represented $43 \%$ of the annual area burned.

High severity wildfire represented over $20 \%$ of the total area burned in 1989, 1990, 2002, and 2003 and less than $5 \%$ of the total area burned in 1984, 1986, 1993, 1997, 1998, 2000, and 2005. The proportion of high severity wildfire peaked in 1989 where $24 \%$ of the total area burned is represented by high severity wildfire. High severity wildfire covered a larger portion of burned area in 1989 (21\% moderate, 25\% high) and 1990 (20\% moderate, $21 \%$ high) than moderate severity.

We found a decreasing trend in the average proportion of low severity wildfire since the 1980s (Figure 6). Low severity wildfire represented an average of $73 \%$ of the total area burned in the $1980 \mathrm{~s}$. The decline continued through the $1990 \mathrm{~s}(68 \%)$ and into the 2000 s where an average of $66 \%$ of total burned area is represented by low severity wildfire. This pattern is reflected by an increasing trend in the proportion of moderate and high severity wildfire.

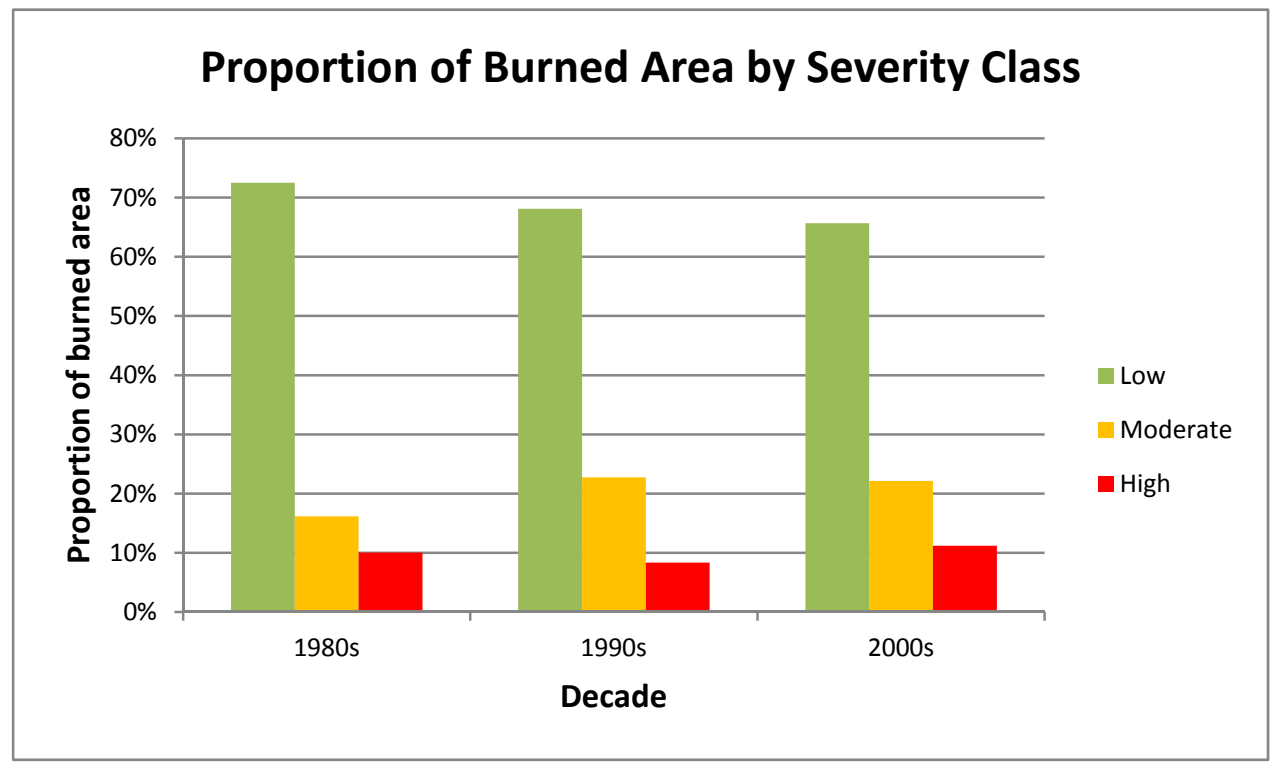

Figure 6. Proportion burned area per decade by low, moderate, and high severity fire

Increasing Fire Season Length 
Previous research determined the length of the wildfire season has been increasing since the early 1980s (Westerling et al., 2006). Our results indicated that the average fire season length has increased by nearly 2 months since 1984. Similarly, Westerling et al., (2006) found that the average fire season length in the western United States increased by 78 days from 1970 to 2003. Beginning in 2001 the region has been experiencing large fire events in April. While the 1980s and 1990s total over 10 thousand hectares burned in the spring, a noteworthy increase exists for the 2000 decade with nearly 35 thousand hectares burned (Figure 7).

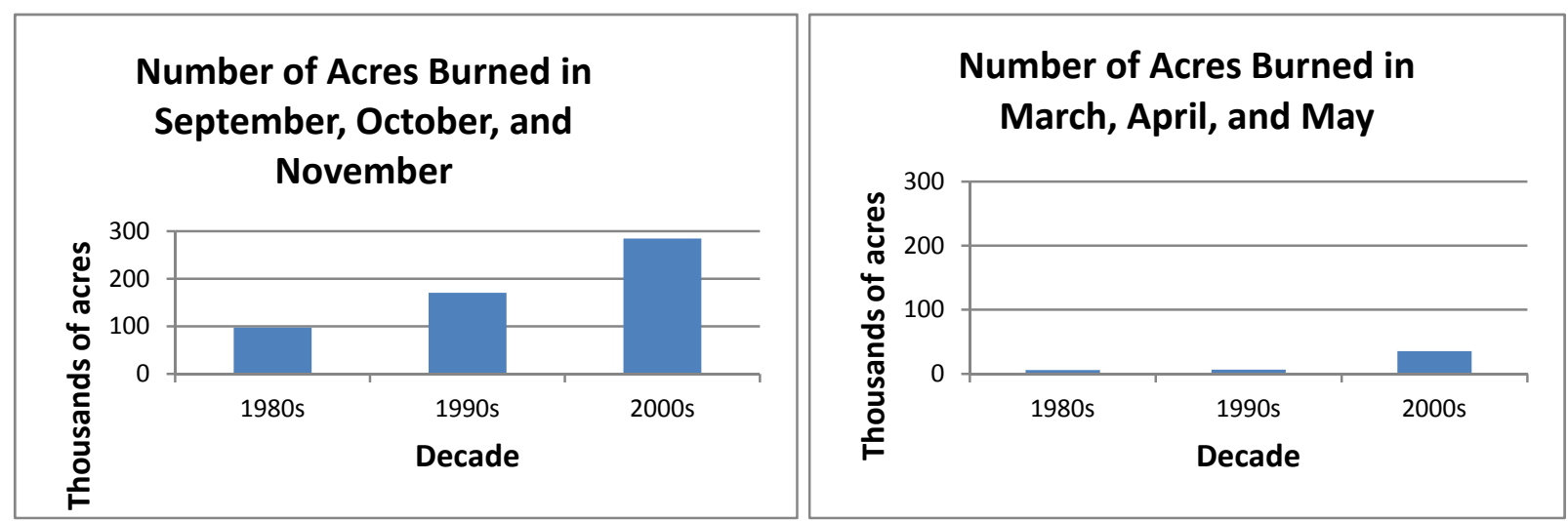

Figure 7. (A) Acres burned in September, October, and November by decade and (B) Acres burned in March, April, and May by decade

We found that fall fire activity has been increasing since the 1980s including fires burning as late as November beginning in 1999. Additionally, there is an increasing trend in hectares burned in September, October, and November. Large fires accounted for nearly 40,500 hectares burned in the 1980s (Figure 7). This increasing trend continues into later decades accounting for over 60,700 hectares burned in the 1990s and nearly 121,400 hectares burned in the 2000s.

Annual fire season duration was determined by subtracting the earliest fire start date from the latest fire start date for each year. Average fire season duration from 1984 - 2008 is 4.2 months. Fire season duration was highest for years 1984, 1988, 1992, 1999, 2001, 2002, 2004, 2006, and 2007 (Figure 7) where each year is associated with a fire season length of 5 months or more. A positive relationship between fire season duration and the number of large fires per year indicates that fire season duration influences the occurrence of large wildfires (Figure 8). 

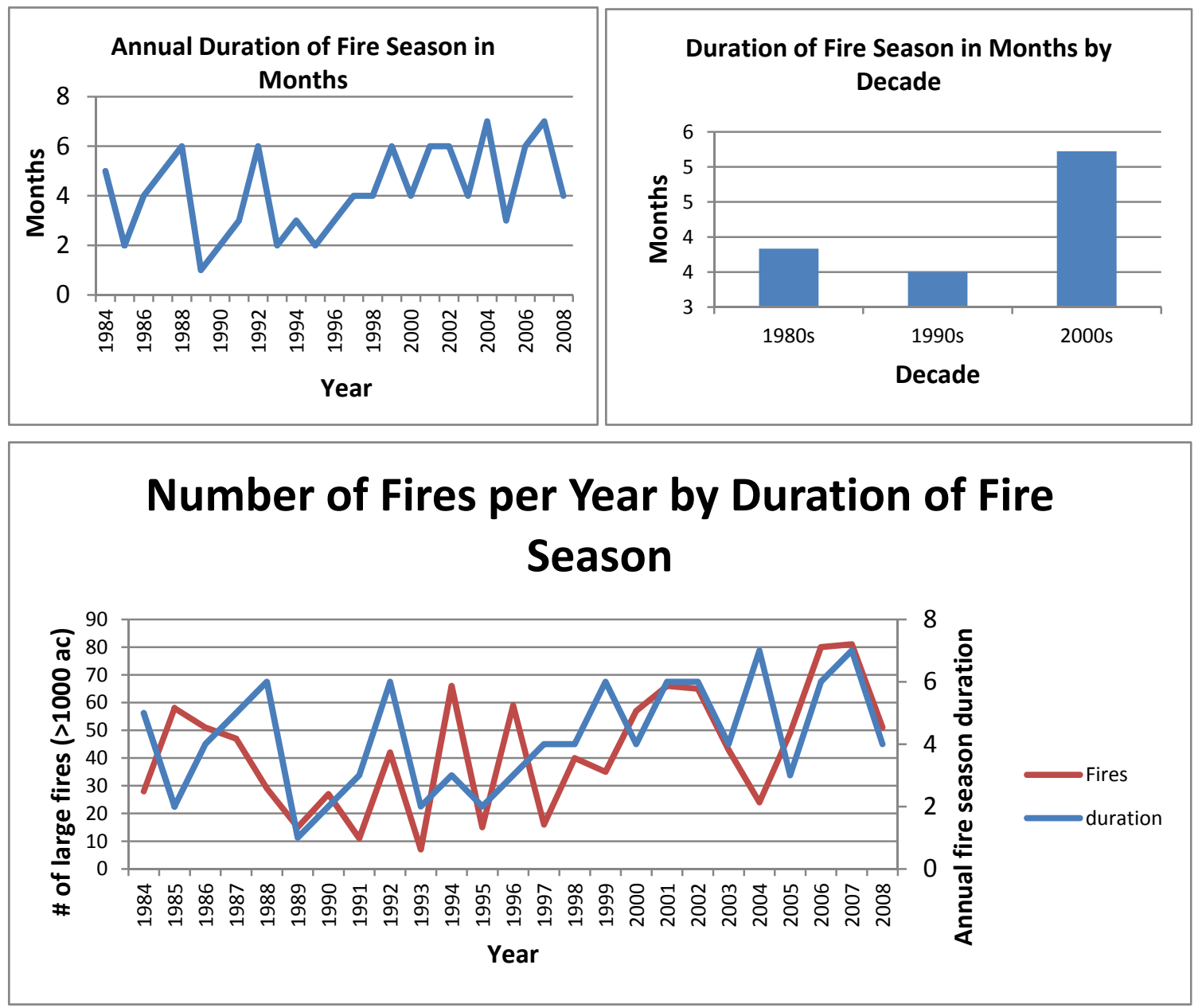

Figure 8. (A) Annual fire season length, (B) fire season length per decade, and (C) number of large fires $(>1000$ acres) per year by fire season length

We find an increasing trend in the average annual duration of the fire season since the 1980s. Fire season duration decreased from nearly 3.8 months in the 1980s to 3.5 months in the 1990 s before increasing to 5.5 months in the 2000s.

\section{Nearest Neighbor Analysis}

We conducted a nearest neighbor analysis to examine the spatial distribution of fire observations in Oregon and Washington. Our results indicated that fires in Oregon and Washington were significantly clustered (Nearest Neighbor Index $[\mathrm{NNI}]=0.66 ; \mathrm{p}<0.01$ ). Nearest neighbor analysis however, does not identify the location of spatial patterning (Wing and Tynon 2008). For this reason, we explored density estimation techniques to identify fire patterns.

\section{Density Estimation}

We performed a quartic kernel density estimation to create a continuous surface representing the density of fire observations across the landscape. Our kernel density results indicated fire hotspots (Figure 9) that strongly correspond to those visible in the fire area map (Figure 1). Notable hotspots are shown in southeast Oregon, Oregon east Cascades, Blue Mountains (northeastern Oregon), Columbia basin (north central portion of northern Oregon and southern Washington), and Okanogan (central Washington). However, unlike nearest neighbor analysis, kernel density mapping indicates variation in point attribute values.

Density diagrams with weighted attribute values indicate variation in hectares and severity across the landscape (Figure 9). The result is a density diagram that considers the spatial distribution of fire centroids, and incorporates the magnitude of hectares burned and fire severity attributes. Similar to fire frequency, burned area hotspots are evident in southeast Oregon, Oregon east Cascades, Blue Mountains, Columbia basin, and 
Okanogan with the exception of a notable hotspot in southwestern Oregon. Further investigation revealed that this hotspot was the result of the 2002 Biscuit fire that burned nearly 200,000 hectares in southwestern Oregon.

Fire Density Acres Density Severity Density
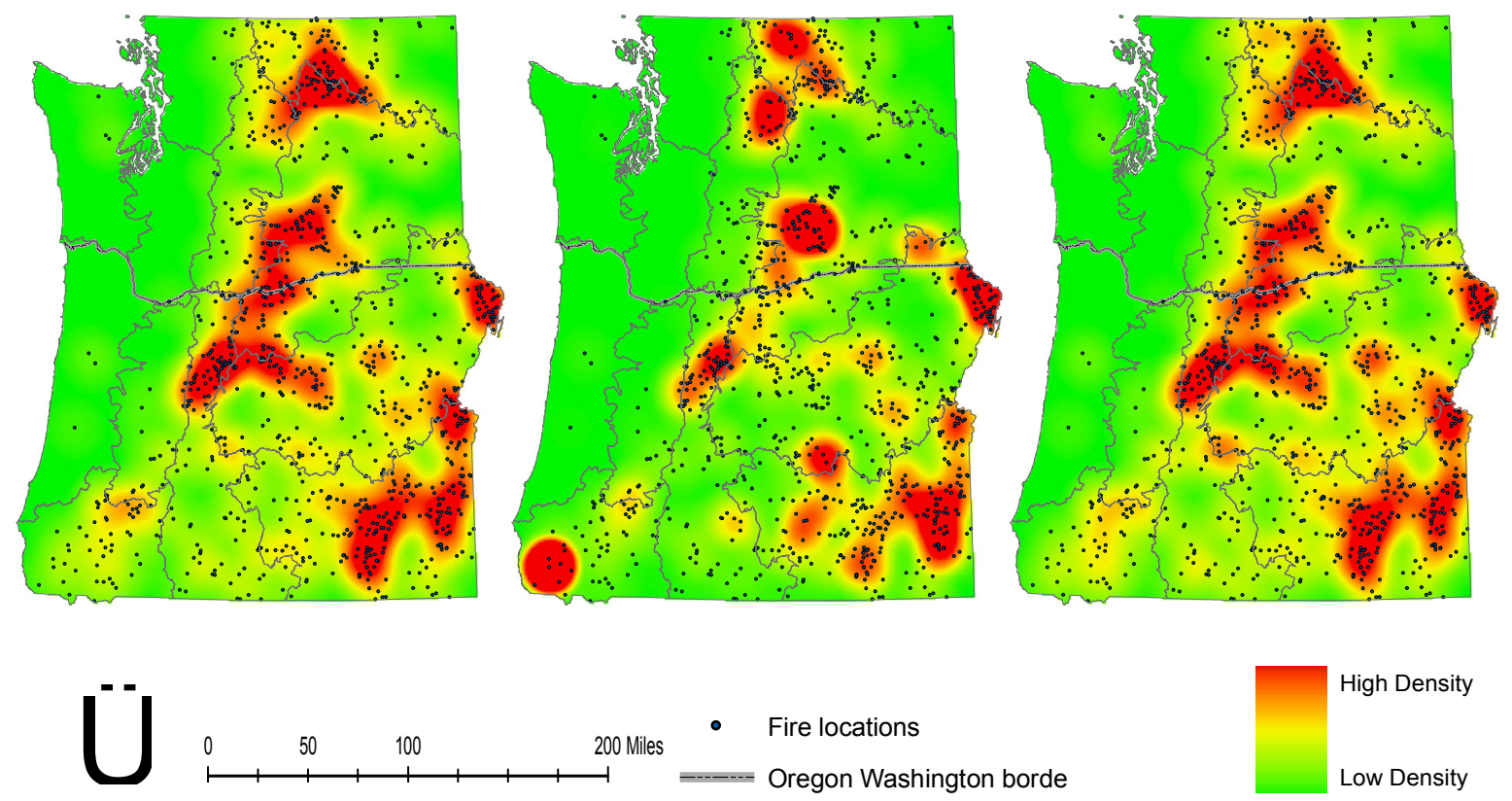

High Density

Figure 9. (A) Quartic kernel density analysis of large fires (>1000 acres) per year (B) annual acres burned, and (C) average fire severity

The severity diagram also strongly related to the density of fire observations (Figure 9). Severity hotspots are evident in Southeast Oregon, Oregon east Cascades, Blue Mountains, Columbia Basin, and Okanogan. However, the diagram illustrated that variation in severity is slightly higher in Oregon east Cascades and Okanogan.

Quadrat analysis

Quadrat analysis is a potentially useful technique for determining the spatial arrangement of point patterns and also has the ability to provide validation for the results of the nearest neighbor analysis. In addition the results of quadrat analysis may provide a visual representation of the spatial distribution of fire centroids across the landscape (Figure 9).

We explored several difference quadrat sizes but based our initial attempt on the approach recommended Boots and Getis (1988) and presented earlier in this manuscript. This resulted in a quadrat size of 80,777 hectares per quadrat which results in a grid overlay containing 530 cells $(23 * 23)$. We experimented with various quadrat sizes before settling with the 530 cell grid. While the 530 cell grid may be appropriate for our analysis, grids containing 100, 225, and 400 cells all indicated similar point distributions.

The results of quadrat analysis indicated a statistically significant clustering pattern among fire observations $(p<0.01)$. These results validate the findings of the nearest neighbor analysis. Furthermore, a diagram indicating the observed cell counts reveals quadrats with high concentrations of fire observations (Figure 10). Several discernible hotspots in Southeast Oregon, Oregon east Cascades, Blue Mountains, Columbia Basin, and Okanogan correspond to the smoothed density surface produced by the kernel density estimation. 


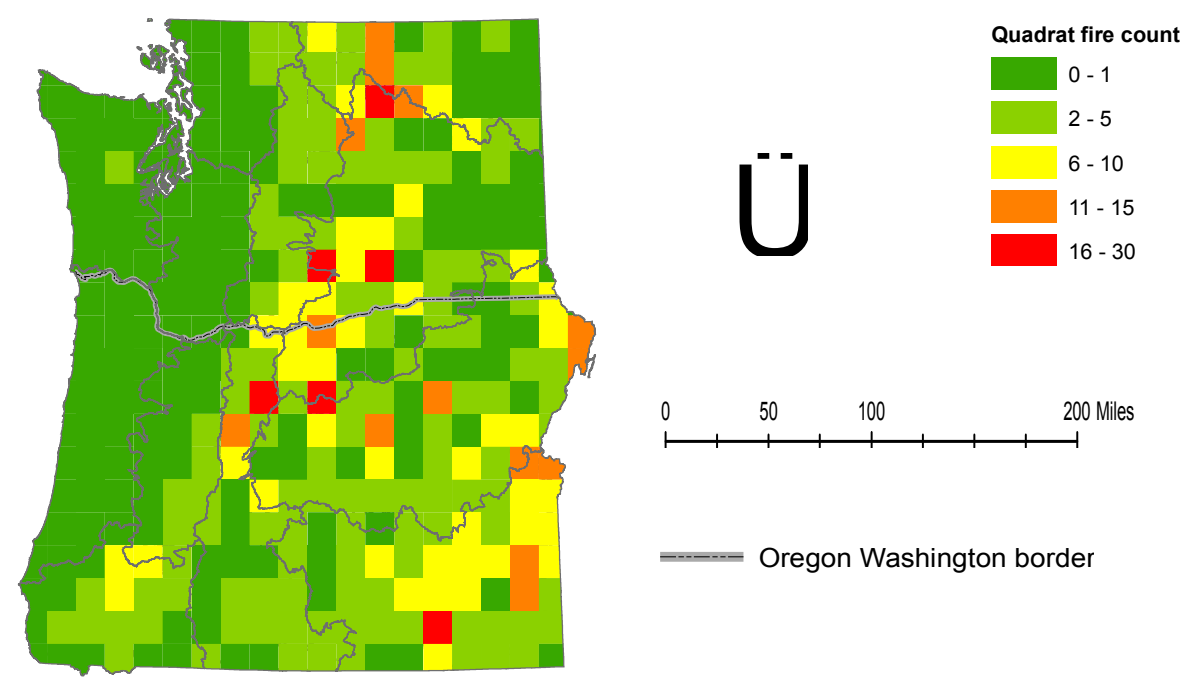

Figure 10. Quadrat analysis of large fires ( $>1000$ acres)

\section{Moran's I}

We used a Moran's Index to determine the similarity of various attribute values between fire locations. Our analysis examined the spatial pattern of fire centroids considering attribute values including; hectares, year, average severity, average dewpoint, average precipitation, average maximum temperature, and average minimum temperature. Results indicated that there is a strong spatial relationship among fires with similar values of year, severity, dewpoint, precipitation, maximum temperature, and minimum temperature (Table 2). In addition there is a mild relationship between fires with similar values in hectares $(\mathrm{p}=0.2)$. However, Moran's I only indicated that similar values occur together.

Table 2. Moran's I and Getis-Ord General G cluster results.

\begin{tabular}{ccc}
\hline Attribute & Moran's I & Getis-Ord \\
\hline Acres & Random & Random \\
Year & Clustered $\mathrm{p}<0.01$ & Cluster High $\mathrm{p}=0.01$ \\
Severity & Clustered $\mathrm{p}<0.01$ & Cluster Low $\mathrm{p}=0.05$ \\
Dpt & Clustered $\mathrm{p}<0.01$ & Cluster High $\mathrm{P}<0.01$ \\
Ppt & Clustered $\mathrm{p}<0.01$ & Cluster Low $\mathrm{p}=0.1$ \\
Tmax & Clustered $\mathrm{p}<0.01$ & Cluster High $\mathrm{p}<0.01$ \\
Tmin & Clustered $\mathrm{p}<0.01$ & Cluster High $\mathrm{p}<0.01$ \\
\hline
\end{tabular}

\section{Getis-Ord General G}

A General G-statistic was statistic was calculated to identify the degree of similarity between similar attribute values. The G-statistic indicated a strong spatial association between fires with similar high values (hotspots) of year, average maximum temperature, average minimum temperature, and average dewpoint (Table 2). In addition, we found a strong spatial association between fires with similar low values (cold spots) of severity. The G-statistic indicates a mild spatial association between fires with similar low values of hectares and precipitation.

Correlations

Our results show that annual burned area is strongly related to the number of fires per year and fire season duration (Table 3). Individual climate variables do not appear to significantly influence annual area burned. However, average maximum temperature has the most significant affect (Table 3). There is a statistically significant positive relationship between total annual hectares burned, number of fires per year, and fire season duration.

Our results indicated that that the length of the fire season is strongly influenced by summer weather conditions. 
No other variable had as many significant relationships as fire season duration. Fire season duration is significantly positively correlated with total annual hectares burned, average annual minimum temperature, average annual dewpoint, and number of fires per year.

There are several significant correlations between climate variables. Positive correlation coefficients for annual average maximum temperature, annual average minimum temperature, and dewpoint indicate that these variables are closely related.

Table 3. Spearman correlation results for annual acres burned, climate variables, number of large fires $(>1000$ acres) and fire season duration.

\begin{tabular}{lllllll}
\hline & Acres & Tmax & Tmin & Ppt & Dpt & \# Fires \\
\cline { 2 - 7 } Acres & 1 & & & & & \\
Tmax & 0.208 & 1 & & & & \\
Tmin & 0.148 & $0.545^{* *}$ & 1 & & & \\
Ppt & 0.149 & -0.300 & 0.055 & 1 & & \\
Dpt & 0.186 & $0.468^{*}$ & $0.966^{* *}$ & 0.164 & 1 & \\
\# Fires & $0.947^{* *}$ & 0.227 & 0.183 & 0.127 & 0.192 & \\
Duration & $0.330^{*}$ & -0.030 & $0.338^{*}$ & -0.012 & $0.361^{*}$ & $0.391^{*}$ \\
\hline
\end{tabular}

Table 4. Spearman correlation results for proportion of burned area by burn severity code.

\begin{tabular}{lllllll}
\hline Severity Code & Acres & Duration & Tmin & Ppt & Dpt & Tmax \\
\hline 1 & $-0.438^{* *}$ & -0.231 & $-0.367^{*}$ & 0.119 & $-0.330^{*}$ & $-0.612^{* *}$ \\
2 & 0.133 & -0.057 & 0.154 & 0.268 & 0.187 & 0.109 \\
3 & 0.033 & 0.300 & 0.120 & $-0.352^{*}$ & 0.010 & 0.322 \\
4 & 0.140 & 0.015 & -0.057 & -0.203 & -0.038 & 0.056 \\
5 & -0.211 & -0.234 & -0.157 & 0.064 & -0.166 & -0.316 \\
\hline
\end{tabular}

Correlation coefficients were determined for each fire severity class by summarizing the proportion of annual of burned area represented in class. Our results indicated that unburned to low severity was significantly negatively related to four variables including; hectares burned, average maximum temperature, average minimum temperature, and average dewpoint. No other severity class was significantly correlated with as many variables. We found a significant negative correlation between moderate severity wildfire and average precipitation.

The results of our point pattern analysis reveal that climate variables and fire observations may not be dependent. The strongest correlation (0.966) occurred between variables occurred between average monthly dewpoint and average minimum temperature (Table 3). Neither fire occurrence nor acreage were significantly related to any climate variable. Average monthly dewpoint and average minimum temperature were significantly related to fire duration however.

We conducted this same analysis but separated our results into burn severity classes. We found that low severity fires (Code 1) were significantly related to all climate variables with the exception of average precipitation. Only one other severity class (Code 3 ) was significantly related to any of the climate variables, and this occurred only in relation to average minimum temperature.

\section{Conclusion}

Historical trends of fire occurrence, size, and intensity can now be studied for forested lands throughout the world using spatial data. These trends can assist forest land managers to better understand the variable nature of fire upon the landscape. Our results indicated that land managers should be prepared to address a range of fire occurrence, as fire trends have varied. Climate databases can also be examined in conjunction with spatial fire trend data to describe past relationships. If climate conditions that appeared to have favored increased fire trends are expected in future years, managers may also want to dedicate increased fire management resources. We encourage similar research that would take into account fire and climate databases that reflect more recent 
temporal periods.

\section{References}

ACSM/ASPRS. Annual convention and exposition technical, 1, 133-143.

Aguilar, F. J., \& Mills, J. P. (2008). Accuracy assessment of LiDAR-derived digital elevation models. The Photogrammetric Record, 23(122), 148-169. http://dx.doi.org/10.1111/j.1477-9730.2008.00476.x

Andersen, H. E., Reutebuch, S. E., \& McGaughey, R. J. (2006). A rigorous assessment of tree height measurements obtained using airborne LiDAR and conventional field methods. Canadian Journal of Remote Sensing, 32(5), 355-366. http://dx.doi.org/10.5589/m06-030

Anderson, E. S., Thompson, J. A., Crouse, D. A., \& Austin, R. E. (2006). Horizontal resolution and data density effects on remotely sensed LiDAR-based DEM. Geoderma 132(3-4), 406-415. http://dx.doi.org/10.1016/j.geoderma.2005.06.004

Carson, W. W., \& Reutebuch, S. E. (1997). A rigorous test of the accuracy of USGS digital elevation models in forested areas of Oregon and Washington. Surveying and cartography.

Chaplot, V., Darboux, F., Bourennane, H., Leguédois, S., Silvera, N., \& Phachomphon, K. (2006). Accuracy of interpolation techniques for the derivation of digital elevation models in relation to landform types and data density. Geomorphology, 77(1-2), 126-141. http://dx.doi.org/10.1016/j.geomorph.2005.12.010

Chen, Q. (2007). Airborne LiDAR data processing and information extraction. Photogrammetric Engineering and Remote Sensing, 73, 175-185. http://dx.doi.org/10.14358/PERS.73.2.175

Clark, R. L., \& Lee, R. (1998). Development of topographic maps for precision farming with kinematic GPS. Transactions of the ASAE, 41(4), 909-916. http://dx.doi.org/10.13031/2013.17247

Cochrane, M. A., Moran, C. J., Wimberly, M. C., Baer, A. D., Finney, M. A., Beckendorf, K. L., Eidenshink, J., \& Zhu, Z. (2012). Estimation of wildfire size and risk changes due to fuels treatments. International Journal of Wildland Fire, 21(4), 357-367. http://dx.doi.org/10.1071/WF11079

Fisher, P. F., \& Tate, N. J. (2006). Causes and consequences of error in digital elevation models. Progress in Physical Geography, 30(4), 467-489. http://dx.doi.org/10.1191/0309133306pp492ra

Gomes, P. L. M., \& Janssen, L. L. F. (1999). Suitability of laser data for DTM generation: A case study in the context of road planning and design. ISPRS Journal of Photogrammetry and Remote Sensingm, 54(4), 244-253. http://dx.doi.org/10.1016/S0924-2716(99)00018-0

Hodgson, M. E., \& Bresnahan, P. (2004). Accuracy of airborne LiDAR-derived elevation: Empirical assessment and error budget. Photogrammetric Engineering and Remote Sensing, 70(3), 331-339. http://dx.doi.org/10.14358/PERS.70.3.331

Hodgson, M. E., Jenson, J., Raber, G., Tullis, J., Davis, B. A., Thompson, G., \& Schuckman, K. (2005). An evaluation of LiDAR-derived elevation and terrain slope in leaf-off condition. Photogrammetric Engineering and Remote Sensing, 62, 415-433.

Holmes, K. W., Chadwick, O. A., \& Kyriakidis, P. C. (2000). Error in a usgs 30-meter digital elevation model and its impact on terrain modeling. Journal of Hydrology, 233(1-4), 154-173. http://dx.doi.org/10.1016/S0022-1694(00)00229-8

Krabill, W. B., Collins, J. G., Link, L. E., Swift, R. N., \& Butler, M. L. (1984). Airborne laser topographic mapping results. Photogrammetric Engineering and Remote Sensing, 50, 685-694.

Kraus, K., \& Pfeifer, N. (1998). Determination of terrain models in wooded areas with airborne laser scanner data. ISPRS Journal of Photogrammetry and Remote Sensing, 53(4), 193-203. http://dx.doi.org/10.1016/S0924-2716(98)00009-4

Leckie, D., Gougeon, F., Hill, D., Quinn, R., Armstrong, L., \& Shreenan, R. (2003). Combined high-density LiDAR and multispectral imagery for individual tree crown analysis. Canadian Journal of Remote Sensing 29(5), 633-649. http://dx.doi.org/10.5589/m03-024

Lefsky, M. A., Cohen, W. B., Parker, G. G., \& Harding, D. J. (2002). LiDAR remote sensing for ecosystem studies. BioScience, 52(1), 19-30. http://dx.doi.org/10.1641/0006-3568(2002)052[0019:LRSFES]2.0.CO;2

Li, J., Taylor, G., \& Kidner, D. B. (2005). Accuracy and reliability of map-matched GPS coordinates: The dependence on terrain model resolution and interpolation algorithm. Computers \& Geosciences, 31(2), 241-251. http://dx.doi.org/10.1016/j.cageo.2004.06.011 
Lim, K., Treitz, P., Wulder, M., St-Onge, B., \& Flood, M. (2003). LiDAR remote sensing of forest structure. Progress in Physical Geography, 27(1), 88-106. http://dx.doi.org/10.1191/0309133303pp360ra

Liu, X. (2008). Airborne LiDAR for DEM generation: Some critical issues. Progress in Physical Geography 32(1), 31-49. http://dx.doi.org/10.1177/0309133308089496

Luccio, M. (2008). Beyond terrain models: LiDAR enters the geospatial mainstream. Imagine Notes Retrieved May 1, 2010, from http://www.imagingnotes.com/go/article_free.php?mp_id=204

McGaughey, R. J., Carson, W. W., \& Reutebuch, S. E. (2004). Direct measurement of individual tree characteristics from LiDAR data. Proceedings of the 2004 Annual ASPRS Conference.

Means, J. E. (2000). Comparison of large-footprint and small-footprint LiDAR systems: Design, capabilities, and uses. Second International Conference on Geospatial Information in Agriculture and Forestry, Lake Buena Vista, Florida.

Miller, J. D., \& Safford, H. D. (2012). Trends in wildfire severity: 1984 to 2010 in the Sierra Nevada, Modoc Plateau, and southern Cascades, California, USA. Fire Ecology, 8(3), 41-57. http://dx.doi.org/10.4996/fireecology.0803041

NOAA (2010). Remote sensing for coastal management. Retrieved May 1, 2010, from http://www.csc.noaa.gov/crs/rs_apps/sensors/LiDAR.htm

Pfeifer, N., \& Briese, C. (2007). Geometrical aspects of airborne laser scanning and terrestrial laser scanning. International Archives of Photogrammetry, Remote Sensing and Spatial Information Sciences, 36(3/W52), 311-319.

Popescu, S. C., Wynne, R. H., \& Nelson, R. F. (2002). Estimating plot-level tree heights with LiDAR: Local filtering with a canopy-height based variable window size. Computers and Electronics in Agriculture, 37, 71-95. http://dx.doi.org/10.1016/S0168-1699(02)00121-7

Reutebuch, S. E., Andersen, H. E., \& McGaughey, R. J. (2005). Light detection and ranging (LiDAR): An emerging tool for multiple resource inventory. Journal of Forestry, 103, 286-292.

Reutebuch, S. E., McGaughey, R. J., Andersen, H. E., \& Carson, W. W. (2003). Accuracy of a high-resolution LiDAR terrain model under a conifer forest canopy. Canadian Journal of Remote Sensing, 29(5), 527-535. http://dx.doi.org/10.5589/m03-022

Sigrist, P., Coppin, P., \& Hermy, M. (1999). Impact of forest canopy on quality and accuracy of GPS measurements. International Journal of Remote Sensing, 20(18), 3595-3610. http://dx.doi.org/10.1080/014311699211228

$\mathrm{Su}$, J., \& Bork, E. (2006). Influence of vegetation, slope, and LiDAR sampling angle on DEM accuracy. Photogrammetric Engineering and Remote Sensing, 72(11), 1265-1274. http://dx.doi.org/10.14358/PERS.72.11.1265

Trimble, (2006). Terrasync software reference manual. T. N. Limited. Westminster, CO. Version 2.60, 1-248.

Trimble, (2007). GeoXT handheld datasheet. Westminster, CO, Trimble: 1-2.

Trimble, (2008). GPS pathfinder office help. Trimble Navigation Limited.

Trimble, (2009a). Trimble GeoXH datasheet. Westminster, Trimble Navigation Limited: 1-2.

Trimble, (2009b). GPS pathfinder ProXH receiver datasheet. Westminster, Trimble Navigation Limited: 1-2.

Van Sickle, J. (2008). GPS for land surveyors. Boca Raton, CRC Press, Taylor \& Francis Group.

Vanicek, P. (1990). Vertical datum and NAVD 88. Retrieved May 14, 2010, from http://www.ngs.noaa.gov/web/about_ngs/history/Vanicek1.pdf

Watershed Sciences. (2008). LiDAR remote sensing data collection: McDonald-Dunn research forest. Corvallis, Oregon, Watershed Sciences Inc.

Yao, H., \& Clark, R. L. (2000). Evaluation of sub-meter and 2 to 5 meter accuracy GPS receivers to develop digital elevation models. Precision Agriculture, 2(2), 189-200. http://dx.doi.org/10.1023/A:1011429815226

Yoshimura, T., \& Hasegawa, H. (2003). Comparing the precision and accuracy of GPS positioning in forested areas. Journal of Forest Research, 8(3), 147-152. http://dx.doi.org/10.1007/s10310-002-0020-0 


\section{Copyrights}

Copyright for this article is retained by the author(s), with first publication rights granted to the journal.

This is an open-access article distributed under the terms and conditions of the Creative Commons Attribution license (http://creativecommons.org/licenses/by/3.0/). 